\title{
The role of fecal calprotectin in pediatric disease
}

\author{
Su Jin Jeong, MD \\ Department of Pediatrics, Bundang CHA Medical Center, CHA University School of Medicine, Seongnam, Korea
}

Fecal calprotectin (FC) is a calcium- and zinc-binding protein of the $\mathrm{S} 100$ family, mainly expressed by neutrophils and released during inflammation. FC became an increasingly useful tool both for gastroenterologists and for general practitioners for distinguishing inflammatory bowel disease (IBD) from irritable bowel syndrome. Increasing evidences support the use of this biomarker for diagnosis, follow-up and evaluation of response to therapy of several pediatric gastrointestinal diseases, ranging from IBD to nonspecific colitis and necrotizing enterocolitis. This article summarizes the current literature on the use of FC in clinical practice.

Key words: Fecal calprotectin, Inflammatory bowel disease, Pediatric gastrointestinal diseases
Corresponding author: Su Jin Jeong, MD Department of Pediatrics, Bundang CHA Medical Center, CHA University School of Medicine, 59 Yatap-ro, Bundang-gu, Seongnam 13496, Korea Tel: +82-31-780-5230

Fax: $+82-31-780-5239$

E-mail: jinped@cha.ac.kr

https://orcid.org/0000-0002-7388-8368

Received: 14 January, 2019

Revised: 14 March, 2019

Accepted: 28 March, 2019

\section{Graphical Abstract}

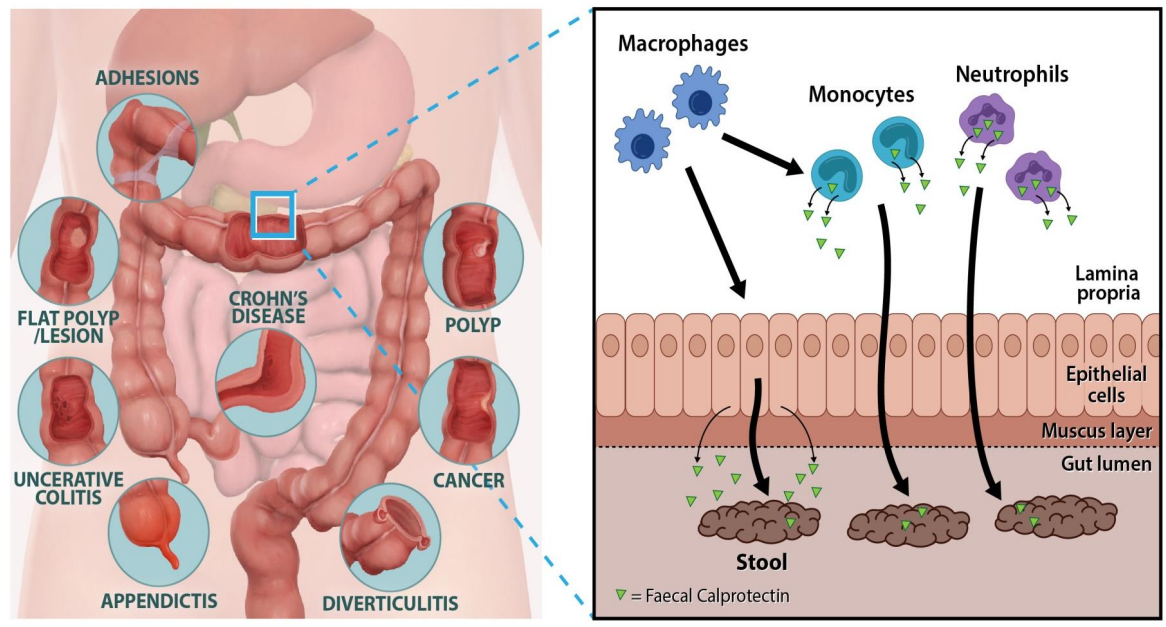

Calprotectin is found in neutrophils, monocytes, and epithelial cells. Transepithelial migration of neutrophils across inflamed gut mucosa followed by cell disruption and release of calprotectin in the gut lumen and its excretion in the feces. It can be used to analyze gut inflammation as well as monitor and predict IBD.

\section{Introduction}

Calprotectin constitutes up to $60 \%$ of the soluble proteins in the cytosols of human neutrophils. In addition, it is distributed in monocytes, macrophages, and epithelial cells. ${ }^{1-3)}$ Their release is activated through interaction of activated monocytes with endothelial cells that increase leukocyte recruitment, and through proinflammatory chemokines by which phagocytes further promote extravasation of leukocytes to the sites of inflammation. ${ }^{4)}$ When measured in feces,
Copyright (C) 2019 by The Korean Pediatric Society

This is an open-access article distributed under the terms of the Creative Commons Attribution NonCommercial License (http://creativecommons.org/ licenses/by-nc/4.0/ which permits unrestricted noncommercial use, distribution, and reproduction in any medium, provided the original work is properly cited. 
calprotectin corelates well with neutrophil infiltration of the intestinal mucosal surface and within the gut lumen, and is a hallmark of digestive inflammatory pathology. ${ }^{5)}$ This protein is able to bind calcium, zinc and manganese ions. Since these elements are of vital importance for bacterial growth, their chelations by calprotectin contribute to the alteration of the gut microbiota, exerting an antimicrobial effect. Through the sequestration of zinc ions $\left(\mathrm{Zn}^{2+}\right)$, calprotectin is also able to inhibit many zinc-dependent enzymes such as matrix metalloprotease, inducing an antiproliferative effect as well as apoptosis in both normal and transformed human and animal cells. ${ }^{6)}$ These properties suggest a pivotal role of calprotectin in inflammatory processes through its effect on the survival and growth of cells. Therefore, fecal calprotectin (FC) is useful as a nonin-

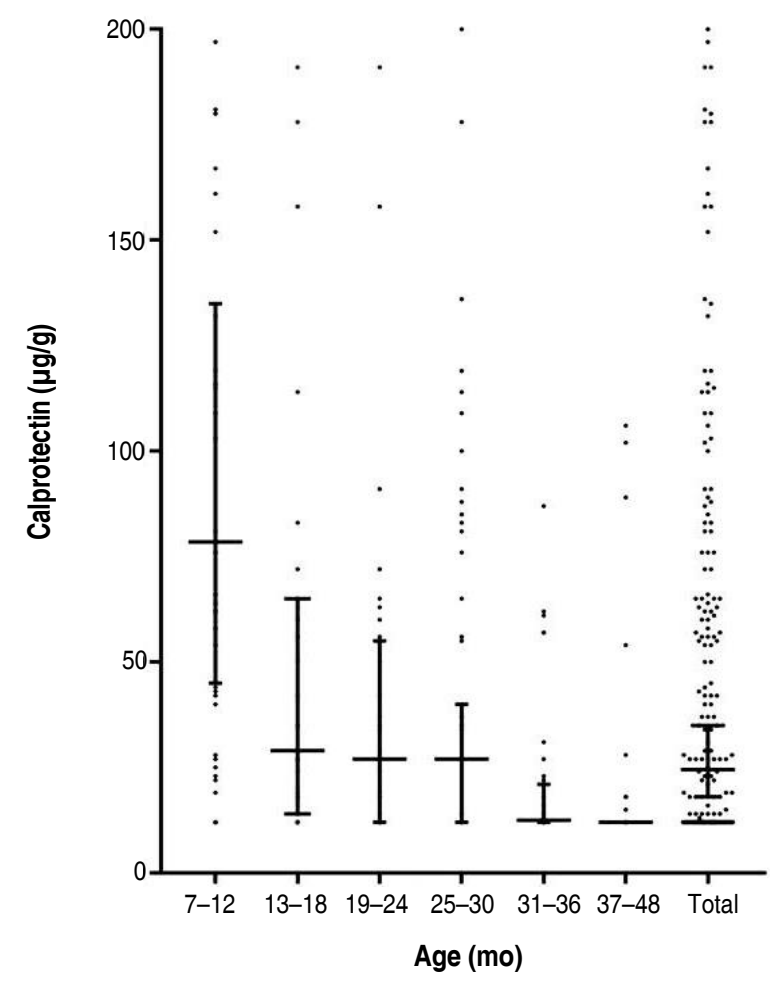

Fig. 1. Diagram of fecal calprotectin levels in healthy children. vasive test reflecting various pathological processes occurring in the intestinal mucosa of pediatric patients.

In addition, its structure is very stable at room temperature for up to 7 days, and is resistant to bacterial degradation. ${ }^{7)}$ This makes calprotectin an ideal marker not only for hospitalized patients, but also for outpatient management.

Numerous studies have been published showing the usefulness of FC in the detection and monitoring of several gastrointestinal (GI) disorders, particularly inflammatory bowel disease (IBD). ${ }^{8-}$

${ }^{10)}$ Differentiating patients with organic diseases from those with functional disorders (i.e., irritable bowel syndrome [IBS]) may be difficult in clinical practice. Indeed, abdominal discomfort including pain, bloating and diarrhea is common, which often arises from functional GI disorders, but may also indicate IBD. When measured in feces, FC can be used to differentiate between nonorganic and inflammatory intestinal disorders, especially to identify IBD. However, it should be noted that elevated FC levels could be found not only in IBD, but also in other GI pathological conditions including infective colitis, microscopic colitis, eosinophilic colitis, colorectal cancer and beyond intestinal disease. ${ }^{11-14)}$

This review aims to explain the role of calprotectin in a range of IBDs and other pathological conditions in pediatric clinical practice.

\section{Cutoff level of FC in clinical practice}

FC levels may vary with age. Currently, an FC level below $50 \mu \mathrm{g} /$ $\mathrm{g}$ is considered normal for children older than 4 years. ${ }^{15)}$ To obtain the mean FC level of children under 4 years of age, we studied FC levels in healthy children at four kindergartens for 6 months. Children were excluded if their parents reported any signs of cold, flu, stomach discomfort, or similar problems in the last 2 weeks. Additionally, children with a history of preterm birth, low or large birth weight, large or small weight for their age (<3rd percentile or $>97$ th percentile), and positive results for stool virus or bacterial polymerase chain reaction were excluded. According to a recent study, newborn infants have high calprotectin levels that later

Table 1. Fecal calprotectin levels $(\mu \mathrm{g} / \mathrm{g})$ in different age groups of healthy children

\begin{tabular}{|c|c|c|c|c|c|}
\hline Age (mo) & No. of subjects & Median $(95 \% \mathrm{Cl})$ & Mean \pm SD $(95 \% \mathrm{Cl})$ & SE & Range $^{\text {a) }}$ \\
\hline $7-12$ & 46 & $78.5(45-135)$ & $145.91 \pm 185.29(90.89-200.94)$ & 27.32 & $12-1,033$ \\
\hline $13-18$ & 39 & $29(14-65)$ & $101.79 \pm 176.12(41.70-158.89)$ & 23.20 & $12-769$ \\
\hline 19-24 & 39 & $27(12-55)$ & $48.79 \pm 68.46(26.66-70.99)$ & 10.96 & $12-301$ \\
\hline $25-30$ & 49 & $27(12-40)$ & $41.41 \pm 46.12(28.16-54.66)$ & 6.59 & $12-200$ \\
\hline $31-36$ & 30 & $12.5(12-21)$ & $23.43 \pm 20(15.96-30.90)$ & 3.65 & $12-87$ \\
\hline $37-48$ & 31 & $12(12-12)$ & $22.97 \pm 26.63(13.20-32.74)$ & 4.78 & $12-106$ \\
\hline Total & 234 & $24.5(18-35)$ & $68.5 \pm 123.12(52.64-3.44)$ & 8.05 & $12-1,033$ \\
\hline
\end{tabular}

$\mathrm{Cl}$, confidence interval; SD, standard deviation; SE, standard error.

a) $\mathrm{A}$ commercially available FEIA (Fluorescence Enzyme Immunoassay) (Green Cross Laboratories, Yongin, Korea) was used to measure quantitatively the concentration of fecal calprotectin. The lower detection limit was $12 \mu \mathrm{g} / \mathrm{g}$, and higher detection limit was $2,000 \mu \mathrm{g} / \mathrm{g}$. 
decline, and usually reach normal levels by the age of 4 years $\left(\right.$ Fig. 1) ${ }^{16)}$. FC levels in a cohort of healthy children aged between 6 months and 4 years were found to be in the 95th percentile with 135 $\mu \mathrm{g} / \mathrm{g}$ in the 7-12 months group, $65 \mu \mathrm{g} / \mathrm{g}$ in the 13-18 months group, $55 \mathrm{\mu g} / \mathrm{g}$ in the 19-24 months group, $40 \mathrm{\mu g} / \mathrm{g}$ in the 25-30 months group, $21 \mu \mathrm{g} / \mathrm{g}$ in the 31-36 months group, and $12 \mu \mathrm{g} / \mathrm{g}$ in the 37-48 months group (Table 1$){ }^{16)}$ The FC level was especially very high and variable in the 0 - to 6-month age category. ${ }^{177}$ In this age, FC levels are affected by feeding and delivery methods. FC values were higher in infants $<6$ months old who were breastfed and born by normal spontaneous vaginal delivery.

\section{Individual and environmental factors affecting FC levels}

High FC levels were reported in individuals with increased body mass index $\left(>25 \mathrm{~kg} / \mathrm{m}^{2}\right)$. The diminished levels of Paneth cell, which plays a key role in the maintenance of the GI barrier, observed in obese subjects may partly explain the local intestinal inflammation. ${ }^{18,19)}$ Dietary supplements such as zinc, vitamin D, and several probiotics can affect FC levels. ${ }^{18)}$ Also, the use of nonsteroidal anti-inflammatory drugs and proton pump inhibitors have been associated with FC elevation. ${ }^{20)}$ The distribution of calprotectin within a stool sample seems to be homogeneous, and measurement of random aliquots give similar results. In addition, day-to-day variability of FC showed low values. ${ }^{21}$

\section{The use of $\mathrm{FC}$ as a biomarker in pediatric GI disease}

Monocytes and intestinal epithelial cells can be activated by different inflammatory triggers such as cytokines or bacterial products, leading to the increased expression and secretion of calprotectin, which can be detected in the stool. Moreover, calprotectin interacts with the toll-like receptor 4 (TLR4) activating macrophages and endothelial cells, and enhancing the expression of several adhesion molecules. In turn, TLR4 is also activated on neutrophils, thereby amplifying inflammation through the release of cytokines, reactive oxygen species and calprotectin again. This process, which involves both phagocytic cells and epithelial cells, leads to neutrophil transmigration and mucosal damage. ${ }^{22,23)}$

\section{Inflammatory bowel disease}

To optimize outcomes in patients with IBD, frequent monitoring is aimed at evaluating treatment efficacy, severity of disease, and risk for potential complications. However, frequent endoscopic assessment of mucosal healing is invasive, time-consuming, costly, and associated with certain risks and discomfort especially in pediatric patients. Therefore, FC has emerged as a new diagnostic tool to detect and monitor intestinal inflammation in children with IBD, as it is a simple, rapid, sensitive, specific, inexpensive, and noninvasive marker of inflammation. Elevated levels are observed in both Crohn disease and ulcerative colitis cases. ${ }^{24)}$ The diagnostic precision of FC for IBD was higher in children than in adults with better accuracy at a cutoff level of $100 \mu \mathrm{g} / \mathrm{g}$ versus $50 \mu \mathrm{g} / \mathrm{g}$ for endoscopically active disease (sensitivity of 81\%, specificity of 69\%). ${ }^{25}$ It is useful as a marker for assessing more accurately the severity of mucosal inflammation as compared to other clinical and laboratory indices. FC cutoff of $250 \mu \mathrm{g} / \mathrm{g}$ had a sensitivity of $60 \%$ and a specificity of $80 \%$ in discriminating large Crohn disease ulcers from small ones. ${ }^{26}$ Treatment of active IBD with glucocorticoids and infliximab-a tumor necrosis factor-alpha antagonists has been shown to decrease FC concentrations, which reach normal levels in 2 weeks in one third of the pediatric patients with IBD, reflecting mucosal healing. FC concentrations fail to return to normal, which indicates continuing inflammatory activity though in a clinically silent disease. ${ }^{27,28}$ This can be used to predict relapse in teenagers with $\mathrm{IBD} .{ }^{29)}$ Although FC plays an important role in the diagnosis, follow-up, assessment of relapses and response to treatment for IBD in children, optimal testing time for monitoring of disease activity and response to treatment needs to be established. In addition, more efforts need to be directed towards the confirmation of absolute cutoff value according to disease location in $\mathrm{CD}$, and disease extent in UC.

\section{Acute infectious colitis}

Infectious diarrhea causes significantly higher FC concentrations than those displayed in IBS which are comparable with the values found in healthy controls. FC levels correlate with the clinical severity of infectious diarrhea in children. A large study including 2,383 consecutive patients with acute diarrhea (sensitivity and specificity of $83 \%$ and $87 \%$, respectively), for FC to identify bacterial infection showed better diagnostic accuracy than fecal lactoferrin and occult blood testing. ${ }^{30)} \mathrm{FC}$ values were higher in acute bacterial diarrhea compared with viral diarrhea both in adults and children. ${ }^{31)}$ Although children with Crohn disease also show higher FC values than children with IBS or infectious diarrhea, repeated testing may be informative for patients with persistent diarrhea or digestive symptoms.

\section{Necrotizing enterocolitis}

In 2010, Thuijls et al. ${ }^{32}$ suggested that FC might be a useful diagnostic marker for necrotizing enterocolitis (NEC). Since then, several studies have investigated its efficacy. FC concentrations exceeding $350 \mu \mathrm{g} / \mathrm{g}$ have been detected, and followed by bowel perforation, bloody stool, and other clinical features of NEC representing signs of GI injury. ${ }^{33)}$ A significant correlation between FC and severity of NEC in preterm infants have also been reported. ${ }^{34)}$ In addition, intestinal fatty acid-binding protein and FC seems to improve the diagnostic accuracy in suspected NEC infants early on in the disease. Moreover, FC decreases as NEC resolves. ${ }^{33)}$ However, the usefulness of FC as such a marker may be controversial owing to high interindividual variations in neonates, especially preterm infants, and lack of data 
regarding specific cutoff values.

\section{Microscopic colitis}

Collagenous colitis (CC) is characterized by a primarily lymphocytic and plasma cellular inflammation of the lamina propria. The high levels of FC in active CC patients can be explained by the fact that calprotectin is present not only in neutrophils, but also in monocytes and macrophages. ${ }^{35)}$ Nevertheless, the use of FC as an inflammatory marker for CC is not recommended due to the lack of universal evidence.

\section{FC: beyond intestinal organic diseases}

There are few data on the potential clinical benefits of FC measurements in groups of individuals with chronic disease at increased risk of GI inflammation outside IBD.

\section{Juvenile idiopathic arthritis}

A recent study showed that FC may be used to evaluate the subclinical intestinal inflammation in children with juvenile idiopathic arthritis. ${ }^{36}$ It is advisable to refer for further investigations only when FC remains significantly elevated in repeated measurements particularly in the absence of overt GI symptoms. Further investigations are warranted to confirm the actual role of elevated FC in these children.

\section{Atopic dermatitis}

The gut immune system is an important regulator of immunemediated diseases, such as allergies. Numerous investigators have shown that changes in the gut microbiota and intestinal inflammation have been associated with the development of allergic diseases. ${ }^{37,38)}$ Altered gut microbiota induces epithelial damage resulting in increased intestinal inflammation, altered gut permeability and immunological balance, which affect the development of allergic diseases and subsequent development of atopic eczema. ${ }^{39)}$ Recent reports showed that elevated FC levels are associated with severity of atopic dermatitis (AD) in children. Also, high FC levels at the age of 2 months had an increased risk of developing $\mathrm{AD}$ by the age of $6{ }^{40)}$ These results suggest that a remarkable intestinal inflammation early in life is a risk factor for the development of allergic diseases later in life. This means that a consist of microbiota colonization appeared to be an important regulator of the intestinal inflammation.

\section{Expert commentary}

FC is a reliable noninvasive tool for assessing intestinal inflammation and plays a relevant role in clinical practice. However, clinicians must be aware that FC levels could be affected by several nonpathological conditions especially in the younger ages. Thus, the following key messages may be highlighted for pediatric clinicians.
- A cutoff of $50 \mu \mathrm{g} / \mathrm{g}$ is widely accepted in children aged from 5 to 17 years. However, in children of less than 5 years, the laboratory results must always be interpreted according to the clinical context, and in case of inconsistent results, FC measurements should be repeated, since age and diet could affect FC values.

- FC could be used to screen for inflammatory disease, and elevated results support the need to select the patients who need further investigation in primary care (colonoscopy).

- FC could be used to monitor the response to drug therapy in patients with chronic inflammatory conditions such as IBD. However, more research is needed to elucidate the evidence-based clinical practice guidelines in tailoring and monitoring drug therapy in patients with IBD.

- Moreover, additional information is warranted in conditions such as microscopic colitis and other inflammatory diseases of the GI tract associated with autoimmune disorders, or allergies owing to the currently limited database.

\section{Conclusion}

The importance of FC in pediatric gastroenterology has increased over time. It provides higher sensitivity, specificity and better information in the evaluation of pediatric IBD than other tests, as well as in the prediction of the clinical course of the disease. Despite many possible functions of FC, its biological function in relation to disease still remains unclear. Further studies are needed to elucidate the clinical relevance of FC in various pathological pediatric conditions and to establish whether FC has any implications beyond its role as an inflammatory mediator.

\section{Conflicts of interest}

No potential conflict of interest relevant to this article was reported.

\section{References}

1. Johne B, Fagerhol MK, Lyberg T, Prydz H, Brandtzaeg P, Naess-Andresen $\mathrm{CF}$, et al. Functional and clinical aspects of the myelomonocyte protein calprotectin. Mol Pathol 1997;50:113-23.

2. Rugtveit J, Brandtzaeg P, Halstensen TS, Fausa 0, Scott H. Increased macrophage subset in inflammatory bowel disease: apparent recruitment from peripheral blood monocytes. Gut 1994;35:669-74.

3. Fagerhol MK. Nomenclature for proteins: is calprotectin a proper name for the elusive myelomonocytic protein? Clin Mol Pathol 1996;49: M74-9.

4. Nisapakultorn K, Ross KF, Herzberg MC. Calprotectin expression inhibits bacterial binding to mucosal epithelial cells. Infect Immun 2001;69:3692-6.

5. Tibble JA, Sigthorsson G, Foster R, Forgacs I, Bjarnason I. Use of surrogate markers of inflammation and Rome criteria to distinguish 
organic from nonorganic intestinal disease. Gastroenterology 2002; 123:450-60.

6. Steinbakk M, Naess-Andresen CF, Lingaas E, Dale I, Brandtzaeg P, Fagerhol MK. Antimicrobial actions of calcium binding leucocyte L1 protein, calprotectin. Lancet 1990;336:763-5.

7. Røseth AG, Fagerhol MK, Aadland E, Schjønsby H. Assessment of the neutrophil dominating protein calprotectin in feces. A methodologic study. Scand J Gastroenterol 1992;27:793-8.

8. Stríz I, Trebichavský I. Calprotectin - a pleiotropic molecule in acute and chronic inflammation. Physiol Res 2004;53:245-53.

9. Poullis A, Foster R, Mendall MA, Fagerhol MK. Emerging role of calprotectin in gastroenterology. J Gastroenterol Hepatol 2003;18:75662.

10. Costa F, Mumolo MG, Bellini M, Romano MR, Ceccarelli L, Arpe P, et al. Role of faecal calprotectin as non-invasive marker of intestinal inflammation. Dig Liver Dis 2003;35:642-7.

11. Licata A, Randazzo C, Cappello M, Calvaruso V, Butera G, Florena AM, et al. Fecal calprotectin in clinical practice: a noninvasive screening tool for patients with chronic diarrhea. J Clin Gastroenterol 2012;46: 504-8.

12. Montalto M, Gallo A, Santoro L, D'Onofrio F, Landolfi R, Gasbarrini A. Role of fecal calprotectin in gastrointestinal disorders. Eur Rev Med Pharmacol Sci 2013;17:1569-82.

13. Widlak MM, Thomas CL, Thomas MG, Tomkins C, Smith S, O'Connell $\mathrm{N}$, et al. Diagnostic accuracy of faecal biomarkers in detecting colorectal cancer and adenoma in symptomatic patients. Aliment Pharmacol Ther 2017;45:354-63.

14. Fagerberg UL, Lööf L, Myrdal U, Hansson LO, Finkel Y. Colorectal inflammation is well predicted by fecal calprotectin in children with gastrointestinal symptoms. J Pediatr Gastroenterol Nutr 2005;40:4505.

15. Oord T, Hornung N. Fecal calprotectin in healthy children. Scand J Clin Lab Invest 2014;74:254-8.

16. Song JY, Lee YM, Choi YJ, Jeong SJ. Fecal calprotectin level in healthy children aged less than 4 years in South Korea. J Clin Lab Anal 2017; 31(6). https://doi.org/10.1002/jcla.22113. Epub 2017 Jan 16.

17. Lee YM, Min CY, Choi YJ, Jeong SJ. Delivery and feeding mode affects fecal calprotectin levels in infants $<7$ months old. Early Hum Dev 2017;108:45-8.

18. Mendall MA, Chan D, Patel R, Kumar D. Faecal calprotectin: factors affecting levels and its potential role as a surrogate marker for risk of development of Crohn's Disease. BMC Gastroenterol 2016;16:126.

19. Kant P, Fazakerley R, Hull MA. Faecal calprotectin levels before and after weight loss in obese and overweight subjects. Int J Obes (Lond) 2013;37:317-9.

20. Poullis A, Foster R, Mendall MA, Shreeve D, Wiener K. Proton pump inhibitors are associated with elevation of faecal calprotectin and may affect specificity. Eur J Gastroenterol Hepatol 2003;15:573-4.

21. Tøn H, Brandsnes O, Dale S, Holtlund J, Skuibina E, Schjønsby H, et al. Improved assay for fecal calprotectin. Clin Chim Acta 2000;292: 41-54.

22. Actis GC, Pellicano R, Tarallo S, Rosina F. Commonalities and differences between Crohn's disease and ulcerative colitis: the genetic clues to their interpretation. Inflamm Allergy Drug Targets 2011;10:447-54.

23. Rosso C, Caviglia GP, Pellicano R. Usefulness of fecal calprotectin determination in pediatric intestinal diseases. Minerva Pediatr 2016;68: 478-86.
24. Caviglia GP, Pantaleoni S, Touscoz GA, Adriani A, Rosso C, Smedile A, et al. Fecal calprotectin is an effective diagnostic tool that differentiates inflammatory from functional intestinal disorders. Scand J Gastroenterol 2014;49:1419-24.

25. von Roon AC, Karamountzos L, Purkayastha S, Reese GE, Darzi AW, Teare JP, et al. Diagnostic precision of fecal calprotectin for inflammatory bowel disease and colorectal malignancy. Am J Gastroenterol 2007;102:803-13.

26. D’Haens G, Ferrante M, Vermeire S, Baert F, Noman M, Moortgat L, et al. Fecal calprotectin is a surrogate marker for endoscopic lesions in inflammatory bowel disease. Inflamm Bowel Dis 2012;18:2218-24..

27. Sipponen T, Savilahti E, Kolho KL, Nuutinen H, Turunen U, Färkkilä M. Crohn's disease activity assessed by fecal calprotectin and lactoferrin: correlation with Crohn's disease activity index and endoscopic findings. Inflamm Bowel Dis 2008;14:40-6.

28. Sipponen T, Kolho KL. Faecal calprotectin in children with clinically quiescent inflammatory bowel disease. Scand J Gastroenterol 2010; 45:872-7.

29. Kallel L, Ayadi I, Matri S, Fekih M, Mahmoud NB, Feki M, et al. Fecal calprotectin is a predictive marker of relapse in Crohn's disease involving the colon: a prospective study. Eur J Gastroenterol Hepatol 2010; 22:340-5.

30. Sýkora J, Siala K, Huml M, Varvařovská J, Schwarz J, Pomahačová R. Evaluation of faecal calprotectin as a valuable non-invasive marker in distinguishing gut pathogens in young children with acute gastroenteritis. Acta Paediatr 2010;99:1389-95.

31. Chen CC, Huang JL, Chang CJ, Kong MS. Fecal calprotectin as a correlative marker in clinical severity of infectious diarrhea and usefulness in evaluating bacterial or viral pathogens in children. J Pediatr Gastroenterol Nutr 2012;55:541-7.

32. Thuijls G, Derikx JP, van Wijck K, Zimmermann LJ, Degraeuwe PL, Mulder TL, et al. Non-invasive markers for early diagnosis and determination of the severity of necrotizing enterocolitis. Ann Surg 2010; 251:1174-80.

33. Selimoğlu MA, Temel I, Yıldırım Ç, Özyaln F, Aktaş M, Karabiber H. The role of fecal calprotectin and lactoferrin in the diagnosis of necrotizing enterocolitis. Pediatr Crit Care Med 2012;13:452-4.

34. Yoon JM, Park JY, Ko KO, Lim JW, Cheon EJ, Kim HJ. Fecal calprotectin concentration in neonatal necrotizing enterocolitis. Korean J Pediatr 2014;57:351-6.

35. Wildt S, Nordgaard-Lassen I, Bendtsen F, Rumessen JJ. Metabolic and inflammatory faecal markers in collagenous colitis. Eur J Gastroenterol Hepatol 2007;19:567-74.

36. Stoll ML, Punaro M, Patel AS. Fecal calprotectin in children with the enthesitis-related arthritis subtype of juvenile idiopathic arthritis. J Rheumatol 2011;38:2274-5.

37. Macdonald TT, Monteleone G. Immunity, inflammation, and allergy in the gut. Science 2005;307:1920-5.

38. Kosiewicz MM, Dryden GW, Chhabra A, Alard P. Relationship between gut microbiota and development of $\mathrm{T}$ cell associated disease. FEBS Lett 2014;588:4195-206.

39. Seo SC, Ahn SH, Ri S, Yoon Y, Byeon JH, Kim SH, et al. Elevated fecal calprotectin levels are associated with severity of atopic dermatitis in children. Asian Pac J Allergy Immunol 2018;36:82-7.

40. Orivuori L, Mustonen K, de Goffau MC, Hakala S, Paasela M, Roduit C, et al. High level of fecal calprotectin at age 2 months as a marker of intestinal inflammation predicts atopic dermatitis and asthma by age 6. Clin Exp Allergy 2015;45:928-39. 